largely to advance modern education; or Owens College, Manchester, whose students show so well the nature of the education they there receive by the honours and prizes they gain at the London University; or many other flourishing colleges-should have their hands strengthened by Government help. In these institutions a thoroughly sound education, in all branches, is given. They have hitherto depended entirely on voluntary support, but the time has come when larger aid is needed to meet the modern requirements. Scholarships given by Government as incentives to work, and as helps to the many industrious students whose means are limited; stipends to professors, in order that they may obtain teaching assistance of a high character, of which they stand sorely in need, for it is absolutely impossible for them to teach effectively the large classes who place themselves under their guidance; grants for apparatus, and enlarged accommodation for the extension of original research-these are subjects which must occupy the attention of any committee appointed to inquire into the existing state of education. It is now pretty generally admitted by scientific men that no exclusively scientific education can meet our present requirements. On the Continent it is felt that it is only in universities and schools where all branches of knowledge are taught, that a really scientific education can be given; and we are glad to find that this opinion has gained ground in this country, together with a conviction that Science studies in their turn render students more apt in the acquisition of other branches of knowledge.

In Germany there is a strong feeling against the establishment of mere technical schools. It is maintained that boys should receive the same training up to a certain stage, and that they should afterwards enter for the special branch they design tofollow. Professor Köchly, of Heidelberg, Professor of Greek, proposes that there should be a thorough but limited instruction in classics, a more extended development of mathematics, a course of instruction in the natural sciences, and systematic instruction in modern languages. Professor Hofmann, who is well known in this country, considers that the best safeguard against the vulgarising of Science, when it is taught with too special a regard to its applications, is to be found in a sound general school training; and he believes that the old gymnasium system is of inestimable value. He asserts that in scores of instances he has seen youths who have come to the chemistry classes in the University of Berlin, with scarcely a knowledge of the meaning of the word chemistry, but who have been well trained in a gymnasium, in a short time completely surpass their fellows, who, in a school of another kind, have acquired considerable knowledge of the elements of chemistry. All the Polytechnic Schools of Germany are rapidly approaching the university type; - the teaching of the principles of Science, and not of the applications, is becoming more and more the main object.

\section{LEONARDO DA VINCI AS A BOTANIST}

$\mathrm{F} E W$ men have better earned the title of universal genius than Da Vinci. An ardent disciple of Nature, disdaining mere superficial knowledge, he went to the root of whatever he took up, and attained an intimate acquaintance especially with everything that bore on his beloved art of painting. And this art was understood by him in its widest sense. Not content with representing the mere outward appearance of Nature or of the human form, he considered it a part of his business as a painter to investigate the laws which produce those appearances or which govern that form in its healthy state. To the long list of his acquirements given in the catalogue of the Louvre collection, as painter, sculptor, architect, engineer, physicist, writer, and musician, may now be added that of botanist. In the first number of a new botanical journal, Nuovo Giornale Botanico Italiano, published at Florence, Sig. G. Uzielli has given some interesting extracts from a work by $\mathrm{Da}$ Vinci, from which he would appear to have anticipated the discovery of certain botanical laws generally attributed to writers of a later age. These extracts are taken from a section of his great treatise on painting, entitled "On Trees and Vegetation," which, however, is found only in one edition of that work, the Roman. The following are the points on which the originality of his observations deserves especial mention.

1. The laws of Phyllotaxis, or of the arrangement of leaves on the stem. Da Vinci appears to have been the first to observe that the order of growth of the leaves is uniform in the same species; and that their modes of arrangement can be divided into three principal forms -.the opposite, the whorled or verticillate, and that usually denominated in text-books the alternate, but which should rather be called the spiral. He also pointed out that in the case of leaves growing in opposite pairs, they are generally arranged in a "decussate" manner, that is, each pair grows at right angles to the pairs immediately above and below it; that when leaves are verticillate, those in each whorl are seldom in a direct line with those in the whorls immediately above and beneath ; and that a very common form of the spiral arrangement is that sometimes called "quincuncial," where the cycle is completed by five leaves, the sixth being in a direct line with the sixth above and beneath. Another observation of the great painter's is, that inasmuch as branches grow from buds generated in the axils of leaves, the arrangement of the branches on the trunk necessarily corresponds to that of the leaves on the stem.

In botanical works it is generally stated that Sir Thomas Browne, in his quaint little treatise "The Garden of Cyrus, or the Quincuncial Lozenge," published in 1658 (a work not mentioned in Pritzel's "Thesaurus Litteraturæ Botanicæ"), was the first to describe the spiral disposition of leaves, which was afterwards noticed contemporaneously by Grew and Malpighi. Bonnet,* however, in x754 followed out the laws of phyllotaxis in a far more exact manner; and the subject has been still further elucidated by Goethe, Schimper, Braun, Steinheil, the brothers L. and E. Bravais, and Martins. To Da Vinci, however, who lived from 1452 to 1519 , is clearly due the priority in the discovery of these laws; although, as might be expected, many of his observations show a crudeness and imperfection which have been corrected by more recent writers.

2. The manner in which, from the structure of the trunk of exogenous trees, their age can be determined. This fact, although now familiar to unscientific persons, appears to have been unknown to the ancients; since Theophrastus makes no mention of it, nor does Pliny, who

* Bonnet, $\mathrm{Ch}$., Recherches sur l'usage des feuilles dans les plantes. 
cites examples of trees which have been known for a great length of time. The discovery is usually attributed to Malpighi and Grew, who published their works, the former in 1675 , the latter in 1682 ; it was, however, known earlier; for Montaigne, passing through Pisa in $158 \mathrm{r}$, learnt the fact from a jeweller of that town, in terms which recall those used by Leonardo. I transcribe the description of Montaigne:-

"The workman, an ingenious man, and famous for the manufacture of beautiful mathematical instruments, informed me that every tree bears as many circles as the years it has lived, and he showed me this in all the specimens of wood which he had in his shop. And the part which is exposed to the north is firmer, and the rings closer and more dense than the rest. By this means he professes to be able to judge of any piece of wood that is brought to him, both the age of the tree, and in what situation it grew." *

The following are the words of Leonardo:-

"The southern part of the plant shows more vigour and youth than the northern. The rings of the branches of trees show how many years they have lived, and their greater or smaller size whether they were damper or drier. They also show the direction in which they were turned, because they are larger on the north side than the south; and for this reason the centre of the tree is nearer the bark on the south than on the north side."

From this it will be seen that both the observations on the age, and those on the eccentricity of the trunks of trees, attributed hitherto by De Candolle $t$ and others to Malpighi, had been previously made by Leonardo da Vinci.

3. The growth of exogenous stems by the formation of new wood beneath the bark. This he describes in the following sentence :-

"The growth in the size of plants is produced by the sap, which is generated in the month of April between the outside coating (camisia) and the wood of the tree. At the same time this outside coating becomes converted into bark, and the bark acquires new crevices of the depth of the ordinary crevices."

It will be seen that, although the painter correctly indicated the portion of the trunk in which the increase takes place, he nevertheless failed to detect the cambium, and the important part which modern researches have shown that it plays in the formation of new wood.

For the above illustrations of the botanical knowledge of $\mathrm{Da}$ Vinci, we are mainly indebted to the article already named by Uzielli, who states that he might cite from the "Treatise on Painting" many other observations, generally correct, on the structure and development of plants, on the symmetry of their secondary axes, and on the influence which external agents have upon their growth. Uzielli remarks that it is strange that Venturi does not mention these botanical observations, he having had Leonardo's MSS. for a long time under his hand, not even referring to them in his "Essay on the physicomathematical works of Leonardo da Vinci," where he claims for the painter the character of a great savant, and one of the founders of the experimental method. Amoretti, and all the other illustrators of his life and

Journal of Travels in Italy, by M. Montaigne.

+ Organographie végétale, vol, 1. p. 324. Paris, 1827. works, are also silent; and Libri, who wrote after the publication of the Roman edition of the work on Painting, mentions only that Leonardo records in it some botanical observations. Libri was, however, the first to publish the important experiments of $\mathrm{Da}$ Vinci relative to the action of poison on plants, discovered in the MSS.* preserved in the Library of the Institute at Paris, in which he also alludes to an ingenious process of drying plants, and reproducing their form easily on paper. Not only these MSS., but those also in the Ambrose Library at Milan, in the British Museum, and at Windsor, and those to be found in some private libraries, would doubtless repay a more careful research than has at present been bestowed upon them; and we would commend the subject to the attention of whoever takes up the thread of the life of Da Vinci, broken by the lamented death of Mr. B. B. Woodward.

Sir Charles Lyell † refers to Leonardo da Vinci as one of the first who applied sound reasoning to the facts of Geology, and who taught the organic origin of fossils. $H$ is botanical and geological theories are alike evidence of the spirit in which he applied all the powers of his mind to the observation of the phenomena that surrounded him, and which prompted him to counsel his pupils and readers invariably to have recourse to Nature rather than to the works of man, as their guide and the source of their inspiration.

ALFRED W. BENNETT

\section{THE RACES OF INDIA}

Memoirs on the History, Folk-lore, and Distribution of the Races of the N.W. Provinces of India. By the late Sir Henry M. Elliot. Edited by J. Beames. (2 vols. Trübner and Co.)

THE above work dates from the time of the old East India Company, bearing ample witness anew to that glorious fertility of genius produced in the full flow of an activity directed seemingly to the development of a purely mercantile policy of the most practical kind-the utilising of a distant continent for the enrichment of a handful of merchants sitting at home at their ease. Such, at least, was the repute enjoyed by the Honourable Court of Directors in their day, and it required no less a change than the transfer of power to as methodical a form of government as that which rules India nowadays to make us see matters in their true light, and bless the memory of John Company. This remark is made, of course, from a scientific point of view, for in every other respect, doubtless, India has at large been the gainer. The Company had served its term, and had to give way to a more central power in the interest of the empire generally. One cannot help contrasting, however, the times that are gone by, when upon the horizon shone such stars of first magnitude in science and literature as Sir Charles Wilkins, Sir William Jones, Gilchrist, Lumsden, Colebrooke, Wilson, Ballantyne, Charles Philip Brown, Roer, Sprenger, with the days that be, when examination tests of the severest kind are in the ascendant, but followed, alas ! by no apparent results as far as growth of scientific knowledge is concerned, whatever advantage the service generally may be found to derive from them. Men there

\footnotetext{
* MSS. of Leonardo da Vinci, vol. N, fos. II and 7 I.
}

+ Principles of Geology, xoth ed. vol. I. p. $3^{x}$ 